\title{
Erratum to: Thioridazine specifically sensitizes drug-resistant cancer cells through highly increase in apoptosis and P-gp inhibition
}

\author{
Ae-Ran Choi ${ }^{1}$. Ju-Hwa Kim ${ }^{1} \cdot$ Sungpil Yoon ${ }^{1}$
}

Published online: 14 August 2015

(C) International Society of Oncology and BioMarkers (ISOBM) 2015

Erratum to: Tumor Biol. (2014) 35:9831-9838

DOI 10.1007/s13277-014-2278-1

In the original paper, the funding number in the acknowledgment section was incorrectly captured. It was written as NCC1310120 instead of NCC1310210. The corrected funding number is shown below.

\section{Acknowledgments}

This work was supported by a research grant (NCC1310210) from the National Cancer Center, South Korea.

The online version of the original article can be found at http://dx.doi.org/ 10.1007/s13277-014-2278-1.

\section{Sungpil Yoon}

yoons@ncc.re.kr

1 Research Institute, National Cancer Center, 809 Madu 1-dong, Ilsan-gu, Goyang-si, Gyeonggi-do 411-764, Republic of Korea 